\title{
La política monetaria de San Martín en el Perú: papel por una plata ausente ${ }^{1}$
}

\author{
por \\ Dionisio de Haro Romero \\ Universidad Rey Juan Carlos, Madrid
}

El objeto del presente artículo es analizar las iniciativas monetarias que el gobierno de San Martín tuvo que desarrollar para resolver su peculiar paradoja monetaria: máquinas sin plata. El Banco Auxiliar de Papel Moneda desempeñó un papel central en la nueva orientación de la política monetaria, abriendo debates más allá de su breve y tortuosa existencia. Finalmente, errores de planteamiento, ausencia de condiciones objetivas y una gestión más que discutible, acabaron por ahogar y neutralizar los pretendidos esfuerzos reformistas.

Palabras Clave: Historia monetaria; sistema fiduciario; metales preciosos; independencia del Perú; casas de la moneda; banco emisor.

\section{INTRODUCCIÓN}

Son numerosos los temas que quedan aún por investigar en torno a las independencias iberoamericanas ${ }^{2}$. Para el caso de la historia económica y monetaria, las lagunas son, si cabe, más notorias y perceptibles, entre otras razones por las escasas y fragmentadas series estadísticas disponibles de las principales macromagnitudes económicas que impiden, hasta el momento, medir y estudiar de forma más precisa los principales fenómenos económicos y monetarios de la época ${ }^{3}$. La razón es sencilla, y compartida con la Península, el de-

1 Este artículo forma parte del Proyecto de Investigación I+D, Tiempos de Desconcierto. Politica y sociedad en la Independencia del Perú, 1820-1824, Referencia HAR2008-03259, financiado por el Ministerio de Ciencia e Innovación de España.

2 Chust, 2010.

3 Es la percepción de Gelman, 2010: 180. 
rrumbamiento del Antiguo Régimen conduce al apagón estadístico mientras las nuevas formas organizativas tardarán décadas en consolidarse ${ }^{4}$. El presente trabajo surge con la intención de avanzar en la investigación sobre la temática general de fiscalidad, moneda y finanzas en las guerras de independencia latinoamericanas ${ }^{5}$, tomando como objeto de estudio el caso particular del Perú.

El artículo pretende contribuir al debate histórico sobre el problema monetario acercándolo al proceso de Independencia del Perú y responder a interrogantes que aparecen en algunos de los estudios en torno a la formación de los sistemas monetarios nacionales latinoamericanos, y en particular el peruano ${ }^{6}$, durante el primer tercio del siglo XIX: ¿Qué implicaciones monetarias implicó la crisis del sistema imperial?, ¿qué papel desempeñó la guerra como complejo proceso de transformación monetaria?, ¿hubo impulso monetario reformista durante la contienda? y si existió ¿qué alcance real tuvo?

La respuesta a estas y otras preguntas relativas a la historia monetaria de este periodo se pueden obtener a partir del estudio de las iniciativas que despliegan los contendientes, en algunos aspectos con clara virtud reformista, y en el propio estudio histórico, analizando las dificultades con las que se enfrenta el pretendido proceso de transformación en el marco general de guerra que se prolongó casi un lustro.

El trabajo se desarrolla a lo largo de cinco apartados, incluidas las conclusiones. El primero analiza, por una parte, el punto de partida monetario y financiero impuesto por el sistema monetario imperial y, por otra examina el sistema monetario tradicional español y la política monetaria de carácter fiscal que de él se desprende. Asimismo, se ponen en evidencia las crecientes dificultades de liquidez que la lógica económica y la base metodológica del sistema tradicional imponen en todos los territorios del Imperio, incluyendo la Península, agudizándose el problema monetario cuando el sistema entra en su fase terminal. En el segundo de los apartados se estudia el problema de la escasez monetaria para el caso del Perú y se plantea la paradoja monetaria del Protectorado: «máquinas sin plata». El tercer apartado se centra en explicar el modo a través del cual el Protectorado intenta resolver su encrucijada monetaria mediante la puesta en marcha de un haz de iniciativas heterogéneas, combinando medidas tradicionales con otras absolutamente novedosas, como es el caso del Banco Auxiliar de Papel Moneda. Con respecto a la nueva institución

4 Fontana, 1992: 263.

5 Así lo considera Carlos Marichal, en Chust, 2010: 266.

6 El análisis general del proceso de transición económica puede consultarse en Irigoin, 2000; 2010. Gelman, 2009. Contreras, 2004. Para el análisis monetario véase Contreras, 1989. Mitre, 2004. Salinas, 2006. 
acotamos el estudio a su primera fase como entidad emisora, hasta el decreto de extinción del papel moneda de 13 de agosto de 1822. Finalmente, en las conclusiones se subraya la importancia estratégica de esta iniciativa reformista y su alcance real, resaltando, por una parte, las dificultades iniciales impuestas por un debilitado y complejo marco monetario general y, por otra, los errores teóricos de planteamiento, los severos condicionantes impuestos por la guerra y la errática gestión con que se llevó el nuevo establecimiento.

\section{LOS VIEJOS HÁBITOS MONETARIOS DEL IMPERIO ESPAÑOL}

Desde el siglo XVI España se transformó en el principal proveedor de metales preciosos para los mercados europeos ${ }^{7}$, y la unidad monetaria del sistema castellano, el real de a ocho también conocido como peso, tras un rápido y amplio proceso de difusión, se erigió con autoridad como la principal moneda demandada en los pagos internacionales. Sevilla y su antepuerto de Sanlúcar se convirtieron en el corazón de un imperio monetario ${ }^{8}$, capaz de bombear liquidez a modo de «dinero mercancía» desde Amberes hasta los lejanos mercados de Oriente ${ }^{9}$.

Sin embargo, este hecho no significó que España dispusiese de un sistema monetario moderno o de unas instituciones financieras desarrolladas que permitieran la irrupción del sistema capitalista en la economía española, más bien todo lo contrario ${ }^{10}$. Durante el siglo XVI España desplegó un modelo de conquista netamente feuda ${ }^{11}$ de explotación abierta y expansión colonial. Con posterioridad, tras los descubrimientos de los extraordinarios filones de plata de Potosí (1545) y Zacatecas (1548), el modelo económico colonial se asentó sobre un sistema relativamente eficaz de captación y retención de remesas de

7 Sobre metales preciosos, rentas americanas, mercados europeos y oferta monetaria, véase Domínguez, 1974. Fisher, 1985. Morineau, 1984. Kriedte, 1994: 47-68. Tepaske y Klein, 1986-1988. Hamilton, 1983. García-Baquero, 1992; 2003. Cuenca Esteban, 2008. Tedde, 2009.

8 Domínguez, 1974: 318-319. Cipolla, 1999: 112.

9 Cipolla, 1999, reconstruye los caminos de la plata española a través del incipiente sistema comercial internacional entre los siglos XVI y XVIII poniendo de relevancia el hecho de que una moneda imperfecta y fácil de cercenar como el peso acabó convirtiéndose en moneda universal de amplia aceptación en la práctica totalidad del mundo: Milán (1551), Florencia (1552), Amberes (1553), Londres (1554), Venecia (1585), Riga (1579), Prusia (1590), India y China (1650).

10 Para Sardá, 1998: 21, las iniciativas capitalistas en España permanecen aherrojadas.

11 Sobre el modelo de conquista colonial castellana, véase Vilar, 1980. 
oro y plata por parte de la Corona. El fuerte impulso que experimentó el comercio con América en el siglo XVIII, a través del progreso tecnológico en los centros mineros, la implantación de las oficinas de fielato en las casas de moneda y la liberalización comercial de 1778, solo tuvo efectos limitados para la economía peninsular y americana, sin apenas modificar su estructura tradicional.

La «moneda fuerte», o bien tomó el camino de la exportación ${ }^{12}$, o fue retirada de la circulación configurando parte de los «tesoros particulares» ${ }^{13}$, siendo así presa de un intenso proceso de «tesaurización» ${ }^{14}$. La Corona, principal protagonista del drenaje exterior ${ }^{15}$, dedicó las rentas americanas, por una parte, al mantenimiento de la onerosa política militar ${ }^{16}$ y diplomática europea, que requería de un descomunal gasto que apenas reportaba otro resultado que el de mantenerse en una posición disminuida en el escenario internacional ${ }^{17}$; y por otra, a la estructura político-militar de Ultramar a través de los «situados». Ambos factores condenaron a la economía peninsular y americana a una continua escasez de metales preciosos y a una paupérrima circulación de monedas de oro y plata, agravada de forma progresiva por el persistente déficit crónico en la balanza comercial española ${ }^{18}$.

Las autoridades monetarias, con el aparente fin de hacer frente a la salida de capital sin contraprestación, se empeñaron en una política defensiva de prohibiciones a las exportaciones monetarias con parcos resultados ${ }^{19}$. Las reiteradas disposiciones sobre permisos, pagos de derechos y guías de circulación se mostraron como ineficaces medidas con las que disuadir la masiva exportación de capitales. La contradicción residió en que la exportación de metales se fundamentó en la propia política monetaria tradicional consistente en bajas tarifas de las casas de moneda, altos derechos de acuñación, y equivalencias oro/plata durante el siglo XVIII en torno a 1/16,5, sensiblemente desfasadas con respecto a Europa, subvalorando la plata, y, por consiguiente, defen-

12 Puede producirse «extracción con contrapartida», en el caso del pago de importaciones o «extracción sin contrapartida», así define el fenómeno de las sacas Sardá, 1998: 21.

13 Vadillo, 1846: 51.

14 Fenómeno estudiado por Marx, 1976: 156-168 [1859].

15 El Banco de San Carlos y el monopolio de exportación de moneda, véase Canga Argüelles, 1833. Tedde, 1988.

16 Véase Flynn, 1984, para contrastar la relación entre metales y gastos de guerra. Para la importancia de los metales preciosos para la monarquía española, véase Espina Montero, 2001.

17 Prieto y De Haro, 2001; 2004; 2010.

18 De Haro, 2006.

19 Archivo General de Simancas (AGS), Dirección General de Rentas, Extracción de moneda 1564-1806, legajos 4880-4942. 
diendo en el Imperio las existencias de oro, aunque dicha política empujase a la plata a la exportación a gran escala. La política monetaria tradicional no obedeció a principios económicos y monetarios modernos, sino más bien, a razones de orden fiscal y defensa de los depósitos tradicionales, considerando el ramo de la acuñación como un instrumento más de su política de ingresos fiscales. En definitiva, se preservó un sistema monetario incapaz de impulsar el crecimiento económico peninsular y americano a través de una oferta monetaria que proporcionase la liquidez suficiente con la que cubrir los tráficos y garantizar las inversiones. Sin embargo, la política monetaria tradicional, a pesar de considerarse una «política absurda y antieconómica» ${ }^{20}$, no dejó de responder a las exigencias y necesidades de la economía tradicional ${ }^{21}$. A lo largo del último tercio del siglo XVIII y las primeras décadas del siglo XIX, la situación del sistema monetario español, siguiendo a Keynes ${ }^{22}$, se podría caracterizar como el resultado de la incapacidad del Estado central para responder adecuadamente a la demanda de dinero que, de manera natural, surge del propio proceso de transformación económica ${ }^{23}$.

En definitiva, la política monetaria tradicional, lejos de favorecer la modernización del imperio colonial, se convirtió en un serio obstáculo al mantener una oferta monetaria muy restrictiva ${ }^{24}$. A ello hay que unir la escasa implantación de instituciones financieras y bancarias en cuanto a su número y variedad, constituyendo su carencia un serio obstáculo para el crecimiento y desarrollo de la economía peninsular y americana ${ }^{25}$. Siguiendo este análisis, la desinte-

20 Luis Ángel Rojo en el prólogo de la última edición de la obra de Sardá con motivo del cincuenta aniversario de la primera edición, Sardá, 1998: VI.

21 En Vilar, 1980a: 135-163, puede encontrarse un interesante estudio teórico en torno al bullionismo.

22 Keynes describe como economía de intercambio real como aquella que: «usa dinero, pero solo como un lazo neutral entre transacciones de cosas y activos reales, y no le permite participar en los motivos o decisiones». Es decir, la definición de economía de los intercambios reales vendría en contraposición de lo que sería una economía monetaria en la que el dinero, «juega su propio papel y afecta a los motivos y decisiones,... de forma que el curso de los acontecimientos no puede predecirse, tanto en el corto como en el largo plazo, sin un conocimiento del comportamiento del dinero a lo largo del proceso», véase Chick, 1990: 22.

23 Véase Pascual y Sudrià, 2008. Pascual, 2004. Maldonado, 2000. Maluquer de Motes, 1994. La mercantilización de la vida económica solo tuvo cierta importancia en algunas áreas geográficas específicas en las que aparecieron actividades industriales y comerciales de cierta envergadura.

24 Asimismo, hay trabajos teóricos recientes que han remarcado la importancia del desarrollo financiero y monetario en las fases de modernización: Rousseau y Sylla, 2003; 2006. Bordo y Rousseau, 2006. Levine, 2005.

25 Cameron, 1974: 17-19. 
gración imperial, al menos desde esta perspectiva monetaria, significaría una potencial oportunidad de transformación para los nuevos sistemas monetarios y su adaptación a las necesidades de un desarrollo moderno que, por el contrario, sería harto difícil en la lógica monetaria tradicional. Dicho de otra manera, las potenciales virtudes que ofrecía el Imperio con relación a la disponibilidad de un mercado monetario de gran tamaño, articulado en torno a la «moneda fuerte», quedarían superadas con holgura por los efectos perniciosos de una política pensada por parte de la Corona en la retención de las remesas americanas, ya directamente, ya por medio de cargas.

\section{LA PARADOJA MONETARIA DEL PROTECTORADO: MÁQUINAS SIN PLATA}

Antes de tratar la historia monetaria peruana durante la guerra de Independencia es preciso señalar que todas las controversias monetarias ya expuestas en el anterior apartado, en cuanto a los efectos negativos de una política monetaria tradicional sustentada sobre un sistema que impulsa al numerario, de forma natural, hacia la exportación ${ }^{26} \mathrm{y}$ el atesoramiento, estaban también presentes en la economía del Virreinato del Perú, acaso de forma más acentuada. Asimismo la política de prohibiciones y rígidas normas de circulación de numerario metálico apenas llegaron a impedir el intenso tráfico ilegal ${ }^{27}$, que junto a la fuerte corriente exportadora oficial, acabaron por prácticamente «secar» los circuitos monetarios internos peruanos ${ }^{28}$, siendo habitual, en numerosas transacciones mercantiles, la práctica del intercambio real, trueque, o la utilización de algún signo de representación primitivo como fue el caso de ajíes, cacao u otros similares ${ }^{29}$. De esta forma el Virreinato se movió de forma esquizofrénica entre la deflación por escasez de numerario y la inflación debido a la

26 Estado del Producto de la Aduana Nacional de Lima en el bienio de 1819 y 1820, en Archivo General de Indias, en adelante (AGI), Lima 1471.

27 El fraude es generalizado y los medios materiales y humanos con los que se dispone para hacer frente al contrabando comercial y monetario son a todas luces insuficientes. Por ejemplo, no hay partidas de registro superiores a 1.000 pesos en abril de 1820 y la Comisión extraordinaria solo cubre 9 de las 600 leguas de costa del Virreinato. Véase Torata, 1895: 92-95.

28 El problema de la desmonetización de la economía peruana quedará enquistado durante buena parte del siglo XIX, véase Salinas, 2006: 10-13.

29 Observaciones sobre la necesidad de establecer el papel moneda en Lima. Colección Documental de la Independencia del Perú, en adelante (CDIP), XIII. Obra de Gobierno y Epistolario de San Martín, 1971: 256. Para consultar cuestiones relacionadas con la tributación en el circuito interior peruano véase Sala i Vila, 1996. 
difusión de dinero de ínfima calidad. La política monetaria española, al igual que con respecto a la Península, no estuvo a la altura de las demandas requeridas por la economía del Virreinato, fundamentalmente por la presiones ineludibles de la Hacienda Real ${ }^{30}$, convirtiéndose esta en el principal obstáculo para un adecuado desarrollo monetario más acorde con las nuevas pautas económicas.

Para analizar lo que fue la política monetaria en el Perú durante el Protectorado de San Martín vamos a centrar el análisis, de forma particular, por una parte, en el caso de la Casa de la Moneda de Lima ${ }^{31}$ y, por otra, en el novedoso proyecto del Banco Auxiliar de Papel Moneda ${ }^{32}$, principales instituciones monetarias con las que contó el bando patriota una vez asentado su poder en Lima en julio de 1822 .

Con la Expedición Libertadora comandada por el general José de San Martín, y su desembarco en la Bahía de Pisco en septiembre de 1820, Perú inició una guerra en la que el dinero y las necesidades de financiación por parte de los bandos enfrentados adquirieron una máxima dimensión. El Protectorado, ante la necesidad de mantener el nervio durante la larga campaña militar (Nervus belli, pecunia) esperó hacer uso de la Casa de Moneda de Lima, y de la materia prima, la plata, con la esperanza de alcanzar sus objetivos. Sin embargo, pronto chocó con una compleja paradoja monetaria: «máquinas sin plata». Es decir, Lima disponía del instrumento con el que crear dinero al tener a su disposición la ceca, aunque inmediatamente tropezó con el obstáculo de la falta de metales en «pasta» ya que los principales yacimientos y rutas de abastecimiento permanecieron bajo control realista tras el fracaso de la campaña del general patriota Álvarez de Arenales en la primera fase de la contienda ${ }^{33}$.

Con el objeto de ratificar la hipótesis que sustenta la mencionada paradoja monetaria se ha recurrido al estudio de diversas aportaciones. En primer lugar, con relación al posicionamiento de las principales explotaciones argentíferas y auríferas ha sido de gran utilidad el trabajo clásico de John R. Fisher ${ }^{34}$, quien a su vez estudia la tipología y características de la industria minera en el Perú del periodo colonial tardío en base a un documento de 1790, que responde al

30 Estado de la Hacienda del virreinato del Perú en 1804, Torrente, 1829, I: 30-35.

31 Burzio, 1958. Lazo, 2008. Moreyra, 1980. Dargent, 2006.

32 El mejor estudio histórico de dicha institución sigue siendo el clásico trabajo de Camprubí, 1960.

33 Cerro de Pasco queda bajo control realista tras la incursión de Valdés y Carratala desde Jauja en abril de 1822. Arenales fracasará más tarde en la recuperación plena de la región en mayo y finalmente Canterac entrará en la ciudad el 7 de diciembre de 1822, véase García Camba, 1846, I: 386-387, 395-396, 398-409 y 441.

34 Fisher, 1975. 
título de Razón de la matrícula general de mineros ${ }^{35}$. Asimismo añade en el estudio un segundo documento ${ }^{36}$ para el estudio del tamaño y casuística laboral en las explotaciones mineras del Perú. En cuanto a la situación minera, Fisher nos aporta una serie de datos generales de gran interés, al señalar que se trata de un tipo de actividad económica basada en explotaciones a pequeña escala, con numerosos pozos separados entre sí y en un régimen de propiedad minifundista ${ }^{37}$. Tan solo encontramos un cierto grado de concentración en la distribución regional de la producción con un peso porcentual elevado, para la plata, a favor de las intendencias de Tarma y Trujillo (Cerro de Pasco y Hualgayoc), aunque esta última adolecía de un alto número de pozos abandonados y peor dotación de haciendas para el beneficio del metal; y muy elevado para el oro a favor, en este caso, de la intendencia de Huamanga (ver cuadro 1 y mapa 1).

En segundo lugar, con relación a la delimitación de las zonas de influencia del bando patriota y realista, respectivamente, se han consultado tres escritos históricos coetáneos de carácter político-militar ${ }^{38}$ : Refutación que hace el mariscal de campo Don Jerónimo Valdés del Manifiesto que el teniente general Don Joaquín de la Pezuela imprimió en 1821 a su regreso del Perú ${ }^{39}$, Historia de la Revolución Hispano-Americana ${ }^{40}$ y Memorias para la historia de las armas españolas en el Perú ${ }^{41}$. El estado militar a enero de 1821 sitúa al ejército de San Martín en Huaura, con reservas en Supe y avanzadas en Retes y Chancay. Asimismo, Arenales con 1.200 hombres emprendió una amplia campaña por el interior, a través del valle de Jauja, que permite, aunque solo temporalmente tras la derrota de O'Relly el 6 de diciembre de 1820, el control patriota de Cerro de Pasco ${ }^{42}$. Sin embargo, tras los sucesos de Aznapuquio, en que altos oficiales realistas depusieron al virrey Pezuela y entregaron el mando al

35 Razón de la matrícula general de los mineros, minas de plata en labor, minas de plata paradas, minas de oro en labor, minas de oro paradas, minas de azogue en labor, haziendas de beneficiar plata y piruros de beneficiar oro en el reyno del Peru formado por las particulares recibidas por las diputaciones territoriales, 30 de abril de 1790. Fisher, 1975: IV-XV.

36 Estado general de minería, 1799. Fisher, 1975: 34.

37 En cuanto a los ciclos regionales de la producción de plata y la estructura del capital minero es de obligada consulta la obra de Deustua, 1986.

38 El uso realizado de dichas obras se limita al estudio territorial de las campañas militares, dejando de lado los polémicos aspectos de índole histórico-político. De forma complementaria cabe citar a Luqui Lagleyze, 2006.

39 Torata, 1895.

40 Torrente, $1829-1830$.

41 García Camba, 1846.

42 Torata, 1895: 31 . 
Cuadro 1. Matrícula general de mineros y minAs EN LABOr. Perú 1790

\begin{tabular}{|c|c|c|c|c|c|c|c|c|}
\hline $\begin{array}{l}\text { Intendencia } \\
\text { y partidos }\end{array}$ & Mineros & $\begin{array}{c}\text { Minas } \\
\text { de } \\
\text { plata }\end{array}$ & $\begin{array}{c}\text { Minas } \\
\text { de plata } \\
\text { aban- } \\
\text { donadas }\end{array}$ & $\begin{array}{l}\text { Minas } \\
\text { de oro }\end{array}$ & $\begin{array}{l}\text { Minas } \\
\text { de oro } \\
\text { aban- } \\
\text { donadas }\end{array}$ & $\begin{array}{c}\text { Minas } \\
\text { de } \\
\text { azogue }\end{array}$ & $\begin{array}{c}\text { Hacien- } \\
\text { das de } \\
\text { plata }\end{array}$ & $\begin{array}{c}\text { Piruros } \\
\text { de oro }\end{array}$ \\
\hline Lima & 100 & 117 & 70 & & & 1 & 41 & \\
\hline Canta & 10 & 19 & 3 & & & & 5 & \\
\hline Yauyos & 12 & 13 & & & & & 4 & \\
\hline Ica & 19 & 19 & & & & & 4 & \\
\hline Huarochiri & 59 & 66 & 67 & & & 1 & 28 & \\
\hline Huancavelica & 58 & 80 & 215 & & & 2 & 42 & \\
\hline Castrovirreyna & 21 & 29 & 43 & & & & 14 & \\
\hline Cores Isla de Tayacaxa & 16 & 15 & 62 & & & 1 & 9 & \\
\hline Lircay & 14 & 27 & 46 & & & $\begin{array}{l}1 \\
1\end{array}$ & 12 & \\
\hline Hualcamarca & 4 & 5 & 64 & & & & 4 & \\
\hline Atonsuya & 3 & 4 & & & & & 3 & \\
\hline Cuzco & 19 & 19 & & & & & 18 & \\
\hline Tinta & 6 & 6 & & & & & 6 & \\
\hline Cotabambas & 7 & 7 & & & & & 7 & \\
\hline Aymaraes & 1 & 2 & & & & & 1 & \\
\hline Chumbibilcas & 1 & 1 & & & & & 1 & \\
\hline Curahuasi & 4 & 3 & & & & & 3 & \\
\hline Arequipa & 91 & 55 & 46 & 1 & 3 & & 33 & \\
\hline Huantajaya & 11 & 6 & 15 & & & & 7 & \\
\hline Santa Rosa & 8 & & 14 & & & & 5 & \\
\hline Carmen & 9 & 1 & 6 & & & & 2 & \\
\hline Casicsa Paiquina & 6 & 1 & 5 & 1 & 3 & & 2 & \\
\hline Viquirtapa & 4 & 4 & & & & & & \\
\hline Caylloma & 12 & 12 & & & & & 7 & \\
\hline Camaná & 12 & 2 & & & & & & \\
\hline Condesuyos & 29 & 29 & 6 & & & & 10 & \\
\hline Tarma & 172 & 227 & 21 & & & & 150 & \\
\hline Pasco & 103 & 78 & 21 & & & & 102 & \\
\hline Huallanca & 27 & 67 & & & & & 12 & \\
\hline Ribera de Queruparca & 5 & 8 & & & & & 2 & \\
\hline Caxatambo & 13 & 26 & & & & & 10 & \\
\hline Huaylas & 5 & 10 & & & & & 5 & \\
\hline Conchucos & 7 & 14 & & & & & 7 & \\
\hline Rurinchinchay & 2 & 4 & & & & & 2 & \\
\hline R. San Marcos & 2 & 4 & & & & & 2 & \\
\hline R.Sta.Catalina & 1 & 2 & & & & & 1 & \\
\hline Rivera de Sihuas & 2 & 4 & & & & & 2 & \\
\hline Asiento Real de Conchucos & 5 & 10 & & & & & 5 & \\
\hline Truxillo & 165 & 134 & 161 & 2 & & & 82 & \\
\hline Hualgayoc & 106 & 108 & 152 & & & & 61 & \\
\hline Patas & 37 & 16 & 7 & 2 & & & 16 & \\
\hline Huamachuco & 22 & 10 & 2 & & & & 5 & \\
\hline Huamanga & 101 & 38 & 63 & 60 & 3 & 1 & 32 & 121 \\
\hline Huamanga & 33 & 38 & 63 & 21 & 3 & & 20 & 14 \\
\hline Parinacochas & 46 & & & 16 & & & & 84 \\
\hline Cangayo & 1 & & & & & 1 & & \\
\hline Huanta & 21 & & & 23 & & & 12 & 23 \\
\hline & 706 & 670 & 576 & 63 & 6 & 4 & 398 & 121 \\
\hline
\end{tabular}

Fuente: Elaboración propia tomando como base Fisher, 1975: 22. Incluyendo correcciones en los datos de Arequipa. 
GRÁFICO 1. DISTRIBUCIÓN REGIONAL DE LA PRODUCCIÓN MINERA
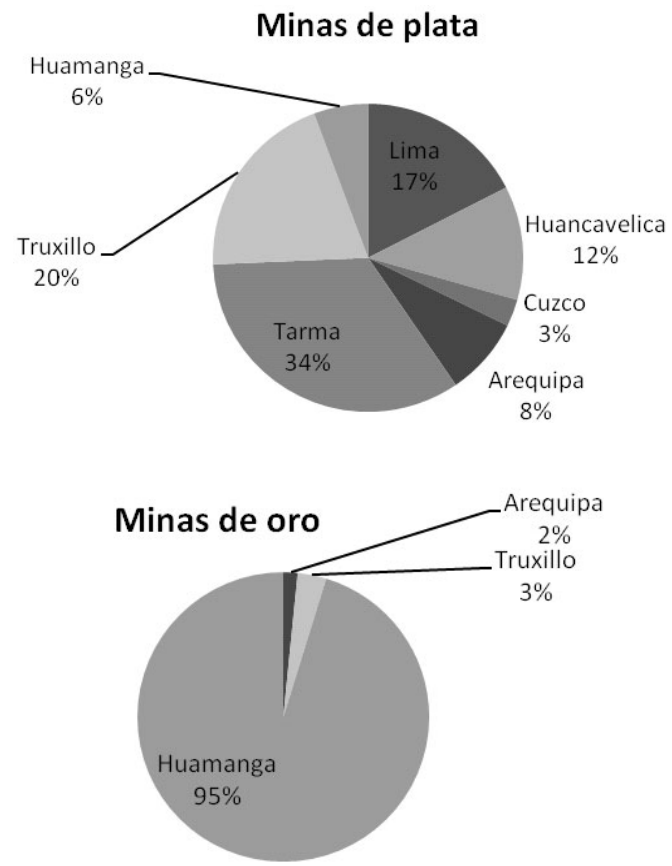

Fuente: Elaboración propia tomando como base Fisher, 1975.

oficial de mayor rango, José de la Serna, hay un replanteamiento de la guerra por parte del bando realista que permitió una gestión flexible de la tensión militar tomando como reservas los recursos de las provincias interiores y estableciendo a modo de nuevo centro de gravedad Cuzco, a la espera de las ansiadas expediciones peninsulares ${ }^{43}$. La derrota de Ica en abril de 1822, el fracaso de la Campaña de Intermedios en octubre del mismo año, el revés de Torata y Moquegua en enero de 1823 y el fiasco más tarde de Santa Cruz en los puertos del sur en julio, dejaron la contienda relativamente estabilizada en términos territoriales con escasas modificaciones hasta las campañas definitorias de 1824 . De esta forma, durante el periodo del Protectorado, de julio de 1821 a septiembre de 1822, el control efectivo del gobierno de San Martín quedó circunscrito a la franja costera desde Lima hasta Trujillo ensanchándose progresivamente hacia el norte comprendiendo regiones interiores y buena parte del centro del país y una estrecha línea hacia el sur hasta los límites con Cañete. Por el con-

43 García Camba, 1846, I: 374-385. 
trario, la administración de La Serna mantuvo durante este periodo un eje estable con el límite norte en Tarma y Chincha, y el sur con Tupiza y Tarija, sostenido mediante los centros militares de Huancayo (Canterac), Arequipa y Puno (Valdés), Cuzco (La Serna) y Oruro (Olañeta) ${ }^{44}$. El desarrollo de la guerra y la disposición de fuerzas permitieron al bando realista contemplar a Lima como objetivo militar en las campañas anuales que se planificaron a partir de abril-mayo de 1823, una vez terminada la estación de lluvias, y que se sustancia con la toma militar temporal en junio de 1823. En definitiva, los principales distritos mineros quedaron bajo control realista (Huancavelica, Tarma, Cuzco, Huamanga y Arequipa) o bien permanecieron en zonas abiertas de difícil gestión por parte de los contendientes (Lima), únicamente Hualgayoc se mantuvo bajo el mando patriota desde el comienzo de la guerra ${ }^{45}$ (mapa 1).

MAPA 1. MinAS y LÍNEAS DE FRONTERA DURANTE LA GUERRA DE INDEPENDENCIA DEL PERÚ

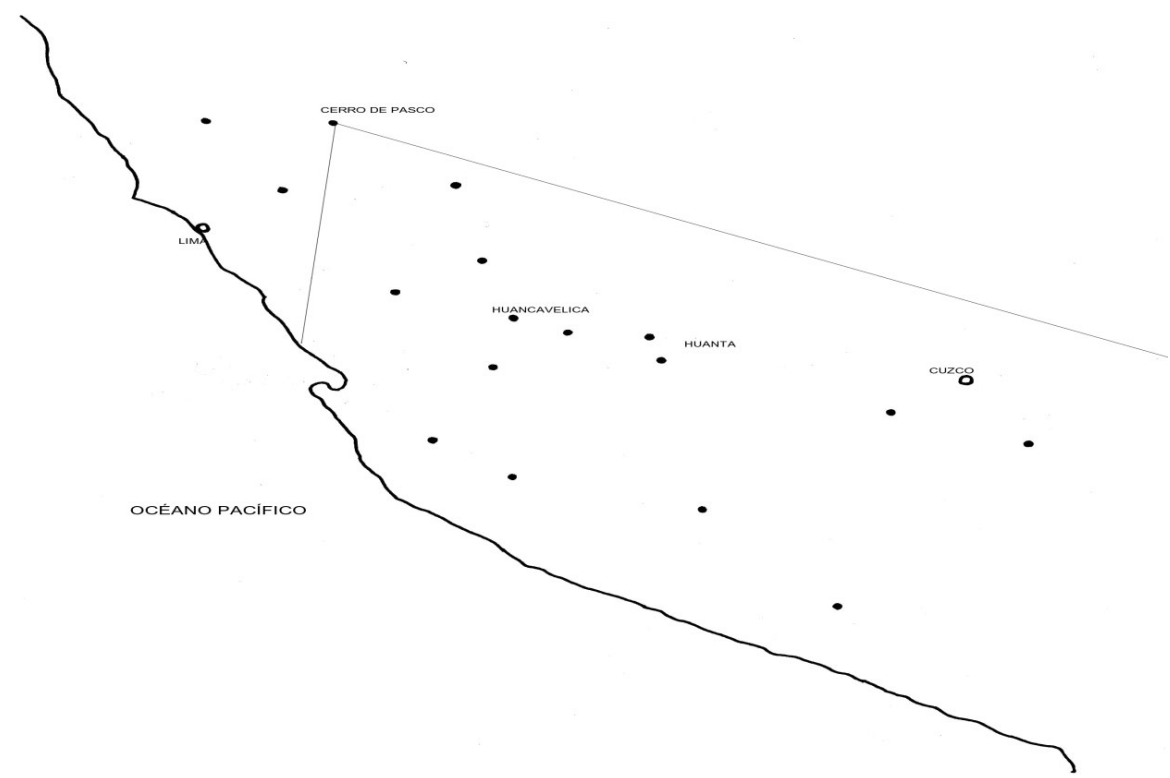

Fuente: Elaboración propia con base en Fisher, 1975. García Camba, 1846.

44 García Camba, 1846, II: 97.

45 Sin embargo, los fondos y pastas en barras en oro y plata remitidos desde Trujillo al gobierno de Lima en el periodo de 1820-1822 son de carácter excepcional. Archivo General de la Nación, Perú, en adelante (AGNP) Sección colonial, Inventario Hacienda Real, Casa de la 


\section{El Banco Auxiliar de Papel Moneda}

La compleja situación monetaria se deterioró muy rápidamente con el inicio de la guerra, y el principal problema monetario con el que se enfrentaba la economía peruana ya desde comienzos del siglo XIX, la extraordinaria escasez de numerario, se agravó de manera extrema a comienzos de 1821. La Ceca de Lima, principal institución monetaria del sistema colonial español en América del Sur, había transitado durante la década precedente con luces y sombras. La Casa de la Moneda permaneció muy rezagada tecnológicamente ${ }^{46}$, obligando a mantener altos derechos de braceaje que unidos a un fuerte señoreaje dejaban como resultado elevados derechos de retención, básicamente saldados por demandantes de «moneda gruesa» ${ }^{47}$. Con respecto a la acuñación, valorada en torno a unos 4 millones y medio de pesos anuales ${ }^{48}$, prácticamente en su totalidad, o bien tomó el camino de la exportación, o fue presa del proceso de «tesaurización». Por un lado, únicamente el numerario chileno desde 1817, como en parte ya ocurría en la Península con la moneda francesa desde la guerra de Independencia ${ }^{49}$, vino a paliar solo de forma limitada el pobre volumen de circulante interior, acabando por ser legal su curso a partir de agosto de 1821. Y por otro, la escasez de numerario fue tan rigurosa que incluso acabó por afectar al comercio minorista limeño, dándose el curioso caso de la creación de las fichas de pulpero, piezas de plomo, u otro material, emitidas por colmados, pulperías y bodegas con el objeto de poder realizar compras que a futuro se hiciesen en el mismo establecimiento que las entregaba como cambio. Estas fichas, generalmente de un cuartillo, acabaron siendo aceptadas como pago por otros comerciantes y el público en general. Las pulperías consolidaron, ante la falta de respuesta oficial, una curiosa red mo-

Moneda de Lima, caja 40, doc. 5; Biblioteca Nacional del Perú, en adelante (BNP), Manuscritos Colonia (en adelante MC), D6166, D6675 y D6683. Asimismo, la situación de los yacimientos de Hualgayoc es muy comprometida desde 1814 como así lo atestiguan expedientes del partido de Pataz, AGI, Lima 1358.

46 A pesar de algunas iniciativas interesantes como son las impulsadas por Pedro Rojas y Briones en 1809, en la adaptación de máquinas para el beneficio de tierras, AGI, Lima 1260.Y Richard Trevithick en 1817, con relación a la adopción de la energía hidráulica en los procesos de acuñación en la Casa de la Moneda de Lima, véase Dargent, 2006.

47 En torno al $96 \%$ del total de la moneda acuñada en la Ceca de Lima corresponde a reales de a ocho. Relación de las rendiciones de moneda de plata, AGI, Lima 1260.

48 Razón de las cantidades de oro y plata acuñadas y compradas en esta Casa de moneda desde el año 1802 hasta el de 1820, Lima, agosto de 1822, BNP, MC, D1025. También encontramos abundantes registros en AGI, Lima 1270.

49 De Haro, 2006: 288-390. 
netaria, a modo de free banking, actuando como entidades emisoras en el estrato inferior de la circulación monetaria y logrando la confianza por parte del público en base a un cierto nivel de capitalización y un autorregulado sistema de emisiones. El modelo aún resistió y compitió eficazmente con los cuartillos emitidos por San Martín en la fase del Protectorado ${ }^{50}$. Hipólito Unanue ${ }^{51}$, ministro de Hacienda del Protectorado, en el correspondiente decreto ratificó la desaparición de los cuartillos de plata de la circulación, la vigencia no permitida de las señas de plomo de los pulperos, y la emisión de la nueva moneda provisional de cobre de un cuartillo a modo de solución definitiva. Todo inútil, la circulación monetaria limeña de carácter fraccionario siguió descansando en unidades de contrastada solvencia y confianza, las «fichas de pulperos», a pesar de su falta de reconocimiento oficial.

En el primer semestre de 1821, la acuñación de plata por parte de la Casa de la Moneda de Lima ya se había reducido a aproximadamente una tercera parte del correspondiente al ejercicio de $1820^{52}$. Tras la proclamación de la Independencia en julio de 1821 el gobierno tuvo serias dificultades a la hora de restablecer los canales monetarios y financieros apropiados con los que continuar el esfuerzo bélico, con una Casa de la Moneda previamente descapitalizada por las fuerzas realistas ${ }^{53}$ tanto en términos técnicos como en caudales.

Las medidas monetarias previas adoptadas por el gobierno, el 9 y 10 de agosto de 1821, tuvieron que ver, primero con el bloqueo monetario y financiero con el fin de frenar la extracción de numerario y fondos ${ }^{54}$; y segundo con la inyección de un fondo extraordinario a la Casa de Moneda con el objeto de

50 Decreto de 18 de febrero de 1822. Monedas de cobre de valor de un cuarto y un octavo de peso. Gaceta del Gobierno de Lima Independiente, 15, 20 de febrero de 1822. CDIP, XIII, Obra de Gobierno y Epistolario de San Martín, 1971: 102.

51 José Hipólito Unanue y Pavón (Arica, 1755 - Cañete, 1833). Naturalista, político y reformador de la medicina. Profesor en medicina de la Universidad de San Marcos (1788), cooperó en la formación de la Sociedad de Amantes del País (1790) y colaboró activamente, a través de diversas publicaciones, en la prensa peruana de la época, como es el caso entre otros de El Mercurio Peruano. Fue principal impulsor de la creación del Colegio Médico de San Fernando (1815) y participó, por parte del virrey, en las negociaciones de Miraflores de 1820. Tras la proclamación de la Independencia es nombrado ministro de Hacienda y en el Congreso Constituyente participará de forma activa en la redacción del proyecto de Constitución de 1823 .

52 Al final del ejercicio de 1821 solo acaban por acuñarse 1.344 .788 pesos frente a los 4.129.500 pesos de media resultante entre los años 1802 y 1815 y 4.001 .608 correspondiente a 1820. BNP, MC, D1025.

53 AGNP, Fondo Republicano, Ministerio de Hacienda, Caja 1, O.L. 9-1-a/b.

54 Ibidem, O.L. 9-4-a/b. 
volverla a poner en funcionamiento ordinario. Por una parte, se exigió la correspondiente guía de Aduana en las extracciones de numerario superiores a cien pesos para el comercio y giro terrestre; por otra, se transfirieron diez mil pesos procedentes de los fondos del Tribunal del Consulado a la Tesorería de la Casa de Moneda para reanudar las operaciones ordinarias de compra de «pastas» $»^{55}$.

Sin embargo, dichas disposiciones tuvieron, con respecto a la primera, una nula incidencia práctica, y en cuanto a la segunda, un efecto muy limitado que pronto se agotó, a pesar de la creación de la oficina de rescate en la estructura de la Ceca con el objeto de estimular la «llevanza de pastas» ${ }^{56}$. Asimismo, la nefasta gestión del envío de sus fondos, por motivos de seguridad, al puerto de Ancón ${ }^{57}$ obligó, una vez más, a adoptar nuevas medidas extraordinarias con las que mantener una mínima actividad en una ceca que inclusive se vio incapaz de pagar los sueldos a sus empleados ${ }^{58}$. Tras dictamen del director, se procedió a habilitar un préstamo de cien mil pesos al seis por ciento de interés, pagaderos en seis meses para volver a hacer efectivo el giro en la $\mathrm{Ceca}^{59}$.

Llegados al punto de bloqueo de las principales partidas de ingresos y agotamiento de las vías ortodoxas de financiación, comenzaron a explorarse, a partir de octubre de 1821, alternativas de financiación heterodoxas con el doble objetivo de, por un lado, hacer frente a los crecientes gastos militares, y por otro, conseguir un mínimo de liquidez con la que sostener la precaria actividad económica interior. En este complejo entorno fue gestado el Banco Auxiliar de Papel Moneda ${ }^{60}$ recogido en las disposiciones del 14 de diciembre de 1821 y 7 de febrero de $1822^{61}$.

La paternidad del proyecto aún no está clara. Mientras Emilio Dancuart se inclina a favor de Hipólito Unanue, Carlos Camprubí hace lo propio con San Martín. El decreto de 14 de diciembre de 1821, en el que se aprueba la creación de la nueva institución, está redactado en primera persona, firmado por San Martín, pero por orden del ministro de Hacienda ${ }^{62}$. No obstante, las numerosas citas a Adam Smith por parte de Hipólito Unanue en diversos decretos,

55 Ibidem, O.L. 9-2; y 9-7-a.

56 Ibidem, O.L. 9-5-a/b.

57 CDIP, XIII, Obra de Gobierno y Epistolario de San Martín, 1971: 125-128.

58 AGNP, Fondo Republicano, Ministerio de Hacienda, Caja 1, O.L. 9-28.

59 Ibidem, O.L. 9-48.

${ }^{60}$ Ley de 14 de diciembre de 1822.

61 CDIP, XIII, Obra de Gobierno y Epistolario de San Martín, 1971: 93-94 y 102.

62 Gaceta del Gobierno de Lima Independiente, 9 de enero de 1822. 
órdenes y memorias de diverso carácter ${ }^{63}$ y el manejo de ideas ilustradas en sus numerosos artículos de prensa ${ }^{64}$ parecen indicar un relativo conocimiento de la obra de este autor clásico a través de las traducciones al castellano realizadas por José Alonso Ortiz, que a su vez compartía edad con el ministro de Hacienda.

El modelo proyectado de sistema fiduciario ${ }^{65}$ tomó como citas genéricas los sistemas de crédito europeos, $\mathrm{y}$, en especial el caso británico, intentando enmarcar su iniciativa monetaria reformista en línea con los sistemas monetarios europeos más avanzados y situando los objetivos de la nueva institución más allá de la mera superación de las urgencias fiscales provocadas por la guerra. Y de manera específica, adoptó como referencia el Ensayo Económico sobre el sistema de la moneda-papel: y sobre el crédito público, de José Alonso Ortiz, obra publicada en Madrid en la imprenta Real en $1796^{66}$. La clave de arco del sistema se sustentó en la confianza del mercado y, para ello, en el escrupuloso cumplimiento de los compromisos de redención desde la esfera pública. Se nombró como director del Banco al conde del Villar de Fuente, y como tesorero y contador a Andrés Salazar y Antonio Álvarez, respectivamente ${ }^{67}$. El plan se respaldó con una garantía a modo de aval de un millón de pesos obtenidos a partes iguales por el Estado, a través de la reforma de la Caja de Censos y por la Municipalidad y el Tribunal del Consulado. El proyecto inicialmente estuvo planteado para un horizonte temporal de no más de dos años con el objeto de cubrir un déficit monetario estimado por la comisión técnica en 4 millones de pesos. El Banco giró papel moneda a partir del 1 de febrero de 1822 con billetes de 8 reales, 10 y 50 pesos, aunque con posterioridad se amplió la emisión a billetes de 4 y 2 reales ${ }^{68}$. El compromiso descansó sobre el saldo por parte del Estado de las obligaciones asumidas en plazo, mitad en metálico y mitad en papel con la emisión de los respectivos vales de 100 y 500 pesos, respetando escrupulosamente la lógica planteada en el siguiente cuadro de redención:

63 Circular de 27 de agosto de 1821, CDIP, XIII, 1, Obra de Gobierno y Epistolario de San Martín, 1971: 81.

64 Para estudiar la prensa peruana de la época véase Martínez Riaza, 1985.

65 CDIP, XIII, 1, Obra de Gobierno y Epistolario de San Martín, 1971: 248-265.

66 Ortiz, José Alonso, Ensayo económico sobre el sistema de la moneda-papel y sobre el crédito público, Lima, Imprenta de los Huérfanos. Orden de reimpresión, 26 de febrero de 1822, AGNP, Fondo Republicano, Ministerio de Hacienda, Caja 1, O.L. 48-5.

67 Circular de 27 de agosto de 1821, CDIP, XIII, I, Obra de Gobierno y Epistolario de San Martín, 1971: 94.

68 Gaceta del Gobierno de Lima Independiente, 25 de mayo de 1822 y 22 de junio de 1822 , respectivamente. 


\section{CUADRO 2. SiSTEMA DE EMISIÓN Y REDENCIÓN}

«Idea de un Banco auxiliar: dispuesto en primer lugar con el objeto de que el ingreso anual de las rentas en dinero se duplique, creando igual cantidad en billetes para hacer pagamentos: en segundo, para rescatar y amortizar aquellos billetes con mitad en metálico y mitad en vales de premio, a saber»:

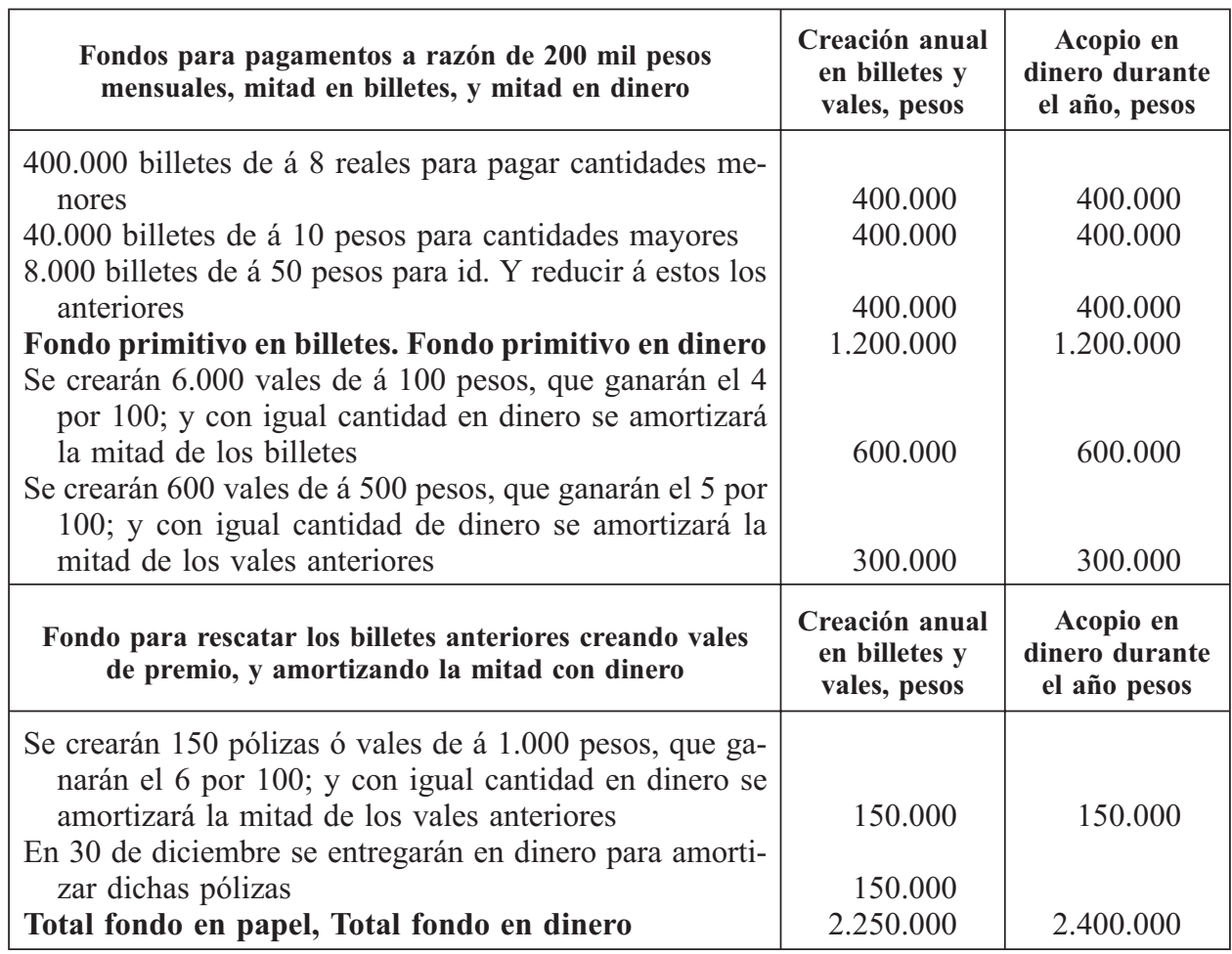

Fuente: Circular de 27 de agosto de 1821, CDIP, XIII, I, Obra de Gobierno y Epistolario de San Martín, 1971: 248-265.

Partiendo de la hipótesis de una acuñación anual de más de 4 millones y medio de pesos se duplicó el dinero con el papel y pagando mitad y mitad se cubrió el caudal necesario para hacer frente a sueldos y gastos. Mediante la creación de vales y rescates en dinero se redimirían las siete octavas partes de los billetes emitidos, exhibiendo fiablemente 150.000 pesos mediante las pólizas indicadas se amortizaría la última octava parte de la deuda quedando cancelado el crédito del año. El sistema conmutaba los billetes menores en mayores a la par y estos a su vez en vales de premios por sus grados, redimiendo la mitad de su valor con dinero en cada plazo resultando recogidos finalmente 
los 457.750 signos de monedas emitidos. El tipo de interés cobrado por el banco de emisión ascendía a un $2 \%$ con el objeto de cubrir los gastos básicos de la operación.

La historia del Banco de Emisión fue analizada y estudiada en detalle por el historiador peruano Carlos Camprubí haciendo uso de gran parte de la documentación existente en archivos públicos y fondos privados ${ }^{69}$. La obra reconstruye de forma fehaciente y detallada la trayectoria histórica del Banco. Recalca la función fiscal de la nueva institución, perdiendo pronto la autonomía preconizada, y el fuerte carácter político con el que fue concebido a modo de medio de afirmación política al servicio del proyecto independiente. Con respecto a estos aspectos, nada hay que objetar a la obra de Camprubí. Sin embargo, el autor achaca exclusivamente a la balanza comercial deficitaria la escasez de numerario en el interior, haciendo abstracción de la lógica del sistema y la política monetaria tradicional. Considera la creación del Banco como un ejercicio democrático, con alta participación de individuos de diferente naturaleza social, política y económica y precursor de una futura base económica y social para la independencia; y califica el sistema de emisión y rescate de billetes como una estructura original, atribuyendo su pronto fracaso a la concatenación de diversos factores exógenos que acaban por arrumbar un proyecto desafiante frente a la realidad local y la experiencia monetaria, pero teóricamente perfecto e impecablemente diseñado.

En cuanto al primer punto, el sistema y la política monetaria tradicional, ya ha sido tratado ampliamente en el primer apartado del presente artículo. La escasez de numerario, no fue solo el resultado del desequilibrio exterior. Al igual que en la Península, la oferta monetaria restrictiva fue consecuencia tanto del persistente déficit de la balanza comercial, como de la propia naturaleza de la política monetaria tradicional.

Con respecto al segundo punto, el proceso democrático de gestación y creación del Banco Auxiliar de Papel Moneda, cabe señalar que aún reconociendo la participación, más indirecta que directa, de un número no desdeñable de personas en la fase preparatoria, quedan serias dudas al punto de considerarlo un proceso radicalmente distinto a las formas tradicionales de participación, y más aún determinar a todo el grupo humano como claramente independentista. Las consultas se apoyaron en la participación de la Municipalidad, junto a una institución de tradición virreinal, el Tribunal del Consulado, que sería suprimido en 1822 y sustituido por la Cámara de Comercio ${ }^{70}$. Por parte de la Municipalidad, no más de 20 personas instruidas acabaron designando a

69 Camprubí, 1960.

70 Hausberger, 2003: 38. Mazzeo, 2006: 63-85. 
cuatro electores: Francisco Moreyra y Matute, Diego Aliaga, Tiburcio de la Hermoza y Miguel Antonio Vértiz. Por parte del Tribunal del Consulado sus representantes fueron: Andrés Salazar, José Antonio Palacios, Antonio Álvarez de Villar y Pedro Abadía ${ }^{71}$. Hipólito Unanue, en calidad de ministro de Hacienda, citó en Palacio el 22 de noviembre a 50 personalidades representativas de la vida económica limeña, con un peso específico como propietarios y hacendados principales ${ }^{72}$. En la fase preparatoria última, durante el mes de diciembre de 1821 trabajaron en paralelo dos comisiones técnicas, una, la designada por la Municipalidad ${ }^{73}$ encargada de establecer las garantías precisas para respaldar la emisión de billetes, y otra nombrada por San Martín a instancias del Tribunal del Consulado ${ }^{74}$, centrada en el diseño de las condiciones financieras y económicas de la nueva entidad emisora. En definitiva, el proyecto monetario se hilvanó a través de un sutil proceso en el que no participaron, directa e indirectamente más de sesenta personas, representantes de dos instituciones, el Tribunal del Consulado y la Municipalidad, y en el que la primera de ellas, sensiblemente disminuida tras la retirada de La Serna de Lima, mantuvo una posición dilatoria y, en algunos casos claramente obstruccionista, ante las nuevas autoridades independentistas. En esta línea el Tribunal del Consulado fue una institución, que al igual que el sector al que representaba, siguió manteniendo una leal adhesión al dominio virreinal ${ }^{75} \mathrm{y}$ el proceso democrático de elección de sus comisionados se dio en el marco tradicional de elección anual de su Junta General. En cuanto a la Municipalidad, era una institución que respondía en cierta forma a los intereses de sectores terratenientes, temerosos del caos y la anarquía que acompañaban a la guerra y de sus imprevisibles consecuencias. En definitiva, es complicado recopilar pruebas fehacientes que ratifiquen la existencia de un proceso realmente democrático en la gestación de la nueva autoridad monetaria. De esta forma, el Banco, en palabras de Carlos

71 Tribunal del Consulado, 30 de octubre de 1821. CDIP, XXI, Asuntos Económicos, I, Informes y Oficios del Tribunal del Consulado, 1971: 72.

72 Por parte de la Municipalidad destacaron: marqués de Montemira, conde de Casa Saavedra, marqués de Villafuerte, marqués de Casa Dávila, conde Vista Florida, conde de las Lagunas, conde de Torre Antigua, conde del Villar de Fuente, conde de Lurigancho y marqués de San Miguel.

73 Compuesta por José M. ${ }^{a}$ Galdiano, Manuel Antonio de Vértiz, conde del Villar de Fuente, Dámaso de Arias y Sanz de Santo Domingo.

74 Compuesta por Andrés de Salazar, Pedro Abadía, Diego de Aliaga, Matías Maestro y Antonio Álvarez del Villar.

75 Cabe resaltar que los priores del Tribunal durante la primera fase independentista, Manuel de Barreda y el conde del Villar de Fuentes acabaron sus días adscritos al realismo en Sevilla, 1836 y El Callao, 1825 respectivamente. CDIP, XXI, Asuntos Económicos, I, Informes y Oficios del Tribunal del Consulado, 1971: XI. 
Camprubí «de carácter político y de afirmación independentista», se impuso desde el gobierno, tras tres meses de trabajos preparatorios, sin el compromiso explícito de los influyentes sectores sociales y económicos limeños, que acabaron por percibir la iniciativa como una mera oficina fiscal de los independentistas $^{76}$. El nuevo nervio de la guerra dependía de la plata enterrada en el interior del país que esperaba de campañas militares exitosas, no de una supuesta base económica criolla que no terminó por liberar los avales a la nueva entidad y cuyas riquezas permanecían expectantes el trascurrir de los acontecimientos. El Banco Auxiliar de Papel Moneda disponía de poco tiempo y desde el primer minuto corrió en su contra.

El modelo teórico de referencia fue la obra de José Alonso Ortiz ${ }^{77}$ titulada Ensayo económico sobre el sistema de la moneda-papel: y sobre el crédito público, en que el autor, buen conocedor de la teoría económica de Adam Smith, plasmó ideas básicas en las que se articulaba la teoría monetaria smithiana.

La idea fuerza que dominaba el ensayo se centraba en las ventajas que suponía para una economía nacional la sustitución de moneda metálica por billetes como medio de abaratar los costes de financiación y transacción, manteniendo como contrapartida un riguroso marco de prudencia y contención monetaria. El libro se estructura en un discurso preliminar y dos artículos. El primero, Sobre la moneda en general, y sobre la de Papel en particular: sus ventajas y desventajas en la pública Negociación; y el segundo, Sobre el Crédito Público. Siguiendo la argumentación teórica que toma como eje la teoría del valor objetiva y considera el dinero como un factor de producción, el papel se convertía en un instrumento clave para su abaratamiento y, en consecuencia, potencial generador de ahorros internos. Ahora bien, para que el sistema funcionase sin interrupciones, sería preciso sumar a la emisión proporcional y a la limitación del número de billetes ${ }^{78}$, la condición de convertibilidad y la precaución de denominación máxima de los billetes.

La reimpresión del Ensayo que se realizó en Lima constaba de dos partes claramente diferenciadas. Una primera, correspondía a una fiel reproducción de la obra original de 1796, y una segunda, comprendía las adiciones sobre el

76 A pesar de la reunión el 24 de diciembre de 1821 de los representantes de la Municipalidad y los priores del Consulado presididos por José de la Riva Agüero, para formalizar una hipoteca de 500.000 pesos destinada a asegurar al Banco emisor, esta quedó de hecho en suspenso sin formalizarse en el futuro, en Gamio, 2005: 314-315.

77 En breve será publicado un artículo de investigación dedicado específicamente al análisis comparativo entre la obra de José Alonso Ortiz y el proyecto peruano de Banco Auxiliar de Papel Moneda.

78 Alonso Ortiz, 1796: 141-142. 
Banco Auxiliar ${ }^{79}$. En esta segunda parte podemos detectar importantes desviaciones teóricas y metodológicas con respecto al modelo original. En primer lugar, en ningún caso encontramos entre las diversas definiciones de moneda-papel que redacta Alonso Ortiz ${ }^{80}$ alusión al tipo de billetes que emitirá el Banco Auxiliar. Los billetes del Banco Auxiliar fueron efectivamente papel-moneda, en cambio, Alonso Ortiz centraba su ensayo en los Vales de Tesorería, tomando como ejemplos los «Vales» y «Medios-Vales de Tesorería» emitidos en España desde 1780, los «Asignates» de Francia y los «Billetes del Echiquer» de Inglaterra. El modelo peruano de papel moneda manejaba una definición laxa de billete, sustentado sobre un sistema mixto de amortización trimestral metálico-fiduciario.

En segundo lugar, en la adición al capítulo sexto De las precauciones para establecer el papel-moneda, del mismo modo que en el texto original, se incluían cinco precauciones: limitar el número de billetes, ceñir los vales al comercio por mayor, y establecer el premio, sobre el fondo de reducción y sobre el fondo de extinción. Con respecto al primer punto, las limitaciones de emisión fijadas a medio plazo en diez y siete millones de pesos y a corto en cuatro y medio, que corresponderían, respectivamente, a la circulación previa de moneda macuquina y al déficit inmediato provocado por la paralización de la ceca, se antojan desmesuradas. Asimismo, se sustituía la debida disponibilidad de dinero efectivo por un complejo y aparentemente seguro sistema de amortización y reintegro que mantendría un teórico equilibrio entre papel y metálico. En cuanto a la segunda precaución, se eliminaba la advertencia de circunscribir la circulación de billetes a operaciones entre comerciantes, evitando su extensión hacia los consumidores. Para el caso peruano no se plantearon inconvenientes a la circulación al por menor. Por último, la cuarta y quinta precaución, sobre los fondos de reducción y extinción, confirmaban el divorcio total con respecto al modelo de referencia al no contemplar ninguna medida al respecto. Los diques de contención que quedaban eran más imaginarios que reales: los deudores del banco se constituían en acreedores, un sistema de reducción y amortización trimestral y un compromiso nunca satisfecho por parte del Estado, la Municipalidad y el Tribunal del Consulado de dotar de garantías al Banco por valor de un millón de pesos.

Como conclusión, se constata una planificación del Banco y del sistema de expansión fiduciaria por parte del Protectorado desde parámetros muy distin-

79 Corresponde a las páginas 165-182 de la obra reimpresa en Lima.

80 Alonso Ortiz, 1796: 62-63. Letras de cambio, billetes de banco (billetes recibidos en el público como dinero en virtud del crédito de sus fondos), notas promisorias, cuentas de caxa, moneda de banco, y vales reales. 
tos a los reflejados en el supuesto referente teórico. Los paralelismos entre la obra de Alonso Ortiz y el proyecto de Banco de Emisión de papel moneda se demuestran más ficticios que reales.

En cuanto al desarrollo de la iniciativa monetaria, el proyecto supuso un sostén financiero estratégico para la administración del Protectorado. Según los datos que nos ofrece la Tesorería General del Estado, el Banco Auxiliar, durante su corto recorrido como emisor, realizó aportaciones mensuales regulares a la Hacienda de San Martín que oscilaron entre los máximos de 100.000 pesos del mes de mayo de 1822 y 10.000 pesos del mes de junio, alcanzando un volumen total de 350.000 pesos antes de la extinción del modelo en el mes de agosto de 1822. Como contrapartida, este extraordinario esfuerzo financiero como oficina fiscal al servicio del Estado vino a explicar el rápido agotamiento del modelo.

Cuadro 3. Saldo de Cuentas del Banco con el Estado a 30 de Julio de 1822

Suplementos de la Dirección del Banco al Estado en papel moneda (en Pesos)

31 de enero

8 de febrero

21 de febrero

1 de marzo

2 de abril

10 de abril

16 de abril

1 de mayo

4 de mayo

31 de mayo

8 de junio

2 de julio

Por el $2 \%$ del suplemento

Deuda Total

Reintegros debidos hacer en metálico

Por el 2\% del suplemento

Por los 100.000 suplidos hasta $1 .^{\circ}$ de mayo

Por los 200.000 suplidos hasta el 8 de junio

Total

Recibidos a cuenta

23 de marzo

22 de junio

26 de junio

50.000

10.000

20.000

20.000

50.000

25.000

15.000

25.000

25.000

50.000

10.000

50.000

7.000

357.000

2 de julio

7.000

75.000

100.000

182.000

Total

Adeudo por plazos cumplidos y por cumplir 
GrÁFico 2. OPERACIONES DEL BANCO CON EL GOBIERNO. RELACIÓN ENTRE ADELANTOS Y DEVOLUCIONES

Operaciones con el gobierno

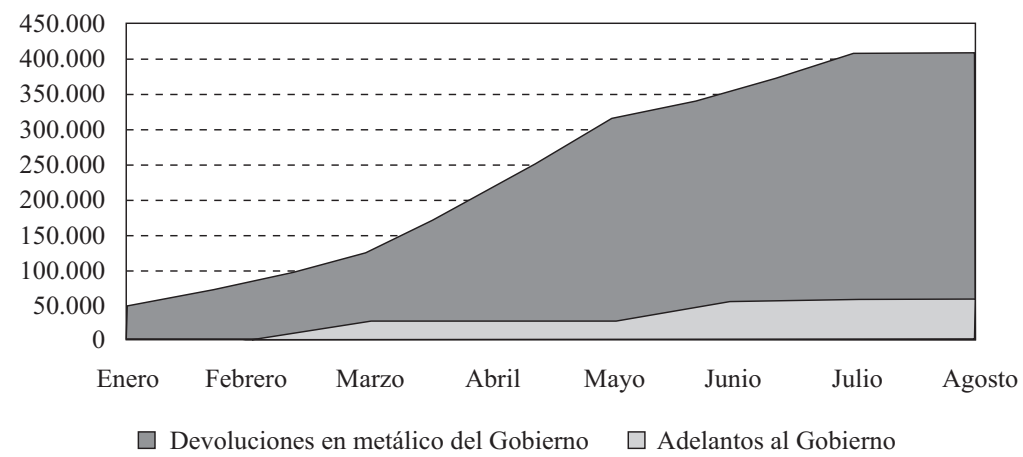

Fuente: AGNP, Fondo Republicano, Ministerio de Hacienda, Caja 8, O.L. 48-31.

Aunque el principal problema en los balances del Banco se centró en sus operaciones con el Estado, estas no fueron las únicas. La deuda por plazos cumplidos de los particulares a finales del verano de 1822 ascendía a 46.886 pesos de un total de 123.000 pesos en suplementos del $2 \%{ }^{81}$. Los temores al más que posible impago de las deudas contraídas por los accionistas conformados en las operaciones de emisión, obligaron al gobierno a decretar medidas extraordinarias, como la obligación de que todo limeño que quisiera abandonar la ciudad fuese acompañado con el correspondiente certificado del Banco que acreditase estar libre de deudas con la entidad emisora ${ }^{82}$. La inobservancia de cumplimento por parte del gobierno $\mathrm{y}$, en menor medida, por los particulares, del complejo sistema de amortizaciones condujeron al Banco a principios del mes de agosto a un punto sin retorno acorralado por la falta absoluta de liquidez y la imposibilidad de ejecutar los avales falsamente contemplados. A partir del vencimiento del segundo plazo en los días 26, 27 y 28 de mayo, en vez de ir sustrayendo de la circulación los billetes circulantes superiores a un peso por vales de premio, el Banco se embarcó por la senda opuesta

81 AGNP, Fondo Republicano, Ministerio de Hacienda, Caja 8, O.L. 48-32.

82 Tras el primer plazo de amortización en los días 28, 29 y 30 de marzo se hacía constar la no concurrencia a amortización de toda la cantidad respectiva a los suplementos hechos desde la apertura del Banco. Aunque el gobierno lo estimaba a modo de confianza por parte del público hacia los nuevos signos de representación, la dirección del Banco Auxiliar prevenía al gobierno de posibles futuros descubiertos. AGNP, Fondo Republicano, Ministerio de Hacienda, Caja 8, O.L. 48-16. 
a la inicialmente concebida inundando, a instancias del gobierno, desde el mes de junio, el circuito monetario de papel menor. Como demuestra la siguiente tabla, la estructura fiduciaria peruana a 8 de agosto nada tiene que ver con la contemplada en decreto de febrero de 1822 . Llegado a este punto el sistema ya era ingobernable.

CUAdro 4. Evolución DE LA ESTRUCTURA DEL PAPEL MONEDA EN CIRCULACIÓN

\begin{tabular}{|l|c|c|c|c|c|r|r|c|}
\hline Papel moneda & 500 pesos & 100 pesos & 50 pesos & 10 pesos & 1 peso & 4 reales & 2 reales & Total \\
\hline 1 de julio & 2.000 & 69.600 & 3.500 & 40.750 & 145.530 & 47.503 & 10.000 & 318.883 \\
30 de julio & 2.000 & 69.600 & 3.500 & 40.750 & 175.430 & 73.653 & 32.050 & 396.983 \\
8 de agosto & 1.500 & 48.200 & 2.050 & 22.090 & 109.790 & 101.102 & 112.251 & 396.983 \\
\hline
\end{tabular}

Fuente: AGNP, Fondo Republicano, Ministerio de Hacienda, Caja 8, O.L. 48-29.

Asimismo, se puso en evidencia la imposibilidad de lograr un mínimo de reservas metálicas en la esfera pública, condición necesaria, con las que sostener el impulso fiduciario. Los reiterados anuncios de cumplimiento por parte del Banco de los trimestres de vencimiento ${ }^{83}$ fueron claramente insuficientes cuando, por otra parte, la Casa de la Moneda permaneció cuasi-paralizada en su función vital de surtir de un mínimo de metálico al mercado y al propio gobierno. La nueva moneda de cobre «provisional» y el metálico con el cuño «Perú Libre», aprobados mediante decretos de 18 de febrero y 15 de julio de 1822 respectivamente, tenían que haber cumplido su función central de sostenimiento del impulso fiduciario ${ }^{84}$. Sin embargo, la presencia metálica en el circuito monetario limeño fue puramente anecdótica, y todo un modelo sustentado en la hipótesis de una rápida recuperación militar de los yacimientos de oro y plata del interior, comenzó a naufragar de forma acelerada cuando la falsificación masiva de billetes de baja y media representación se tornó a gran escala. La dirección del Banco Auxiliar hizo ímprobos esfuerzos con el fin de hacer frente al masivo fraude, entre otros burilando nuevas ediciones ${ }^{85}$, con escasos efectos reales en el mercado. En junio se certificó el derrumbe del sistema

83 CDIP, XIII, Obra de Gobierno y Epistolario de San Martín, 1971: 106-107. 1822.

${ }^{84}$ Gaceta del Gobierno de Lima Independiente, 9 de febrero de 1822 y 17 de julio de

85 En abril de 1822 se detectó una masiva falsificación de billetes de 10 pesos ordenando nuevo estampe desde el número doce mil agregando con tinta negra una línea de letras menores buriladas y en el centro un sello de relieve. Gaceta del Gobierno de Lima Independiente, 17 de abril de 1822. 
cuando el papel moneda ya no fue aceptado en la venta de artículos de primera necesidad ni recibido en las oficinas públicas ${ }^{86}$.

En definitiva, sin base metálica, a falta de condiciones objetivas, acosado por operaciones fraudulentas, y abrumado por extraordinarias emisiones, el experimento fiduciario fracasó sin cumplir el primer semestre de andadura. En el mes de julio de 1822 dio comienzo el debate en torno a la suspensión del modelo monetario de papel-moneda. El sistema, a pesar de sus numerosos inconvenientes, errores y futuras disfunciones, había logrado, mediante la ampliación de la base monetaria mantener en pie a un precario gobierno acorralado por unos gastos militares muy superiores a los inicialmente planificados. De esta forma, el final de la experiencia fiduciaria del Protectorado comprometió directamente la vigencia del pretendido gobierno al que representaba. Una Junta extraordinaria, encargada de estudiar el modo por el cual se procedería a extinguir el papel-moneda en circulación y se redefiniría las funciones del Banco Auxiliar, dictaminó sobre el caso a menos de un mes de la salida de San Martín del Perú. La Junta estaba formada por varios ministros del gobierno, el prefecto del departamento, alcaldes de la municipalidad y vocales de la cámara de comercio. Los debates se iniciaron el 11 de agosto y concluyeron el 13 del mismo mes aprobándose por unanimidad la extinción del papel mone$\mathrm{da}^{87}$. En el citado decreto se contempló el giro, que no fue efectivo sino en una mínima parte de 140.000 pesos a cargo de los comerciantes comisionados con el objeto de consolidar los billetes de 2 y 4 reales, a cargo de reintegros en sus desembolsos con los derechos de aduana. Hipólito Unanue argumentó de forma somera en su Memoria ministerial como factor central del fracaso de la iniciativa monetaria la extraordinaria resistencia por parte del público a recibir papel moneda motivado por el desconocimiento y falta de experiencia histórica. Una explicación a todas luces incompleta, que hacía recaer la responsabilidad del fisco únicamente sobre una demanda no preparada.

\section{CONCLUSIÓN}

La guerra de Independencia en el Perú obligó a los contendientes a buscar alternativas monetarias con las que mantener el esfuerzo bélico. El punto de

86 En el mercado de Lima el papel moneda se desechó en operaciones mercantiles para la adquisición de alimentos al por mayor y funcionarios de la alta Cámara de Justicia y agentes de la hacienda pública rechazaron el cobro mediante este mismo arbitrio. AGNP, Fondo Republicano, Ministerio de Hacienda, Caja 8, O.L. 48-25. 1822 . 
partida se antojó de enorme complejidad en una situación dominada por la escasez pertinaz de numerario resultado de la larga crisis económica «tardoimperial», el prolongado ciclo de guerras, el abultado déficit comercial y la propia naturaleza de la política monetaria tradicional.

El Protectorado se enfrentó a la resolución de una difícil paradoja monetaria: «máquinas sin plata». Tras unos primeros compases prometedores para los patriotas la guerra se estancó durante meses, quedando, por una parte Lima y el norte y la Casa de la Moneda bajo control independentista, y por otra los principales yacimientos de oro y plata bajo el dominio realista afincado en el Cuzco. En una primera fase la financiación del esfuerzo bélico recayó sobre fórmulas convencionales: préstamos del Tribunal del Consulado, contribuciones ordinarias y extraordinarias y donativos. Sin embargo, los límites de estas iniciativas pronto se pusieron de manifiesto con un insuficiente nivel de ingresos fiscales regulares y una irregular y baja actividad de la Ceca, a pesar de la urgente creación del Banco de Rescate y la inyección de sucesivos fondos y créditos con los que mantener un mínimo de operatividad. El Banco Auxiliar de Papel Moneda se erigió en el proyecto monetario que permitiera al nuevo Estado sortear la compleja paradoja trayendo al presente, mediante la emisión de papel moneda, los caudales entonces enterrados en la Sierra Central y el Sur bajo la atenta mirada de los ejércitos realistas.

El modelo proyectado significó la primera experiencia de sistema fiduciario del Perú y, aunque se desarrolló en paralelo al Banco de Descuentos de Buenos Aires, mantuvo unas características propias y singulares que lo convirtieron en un caso único. En febrero de 1822 comenzó su andadura, alentado de forma decisiva por el ministro de Hacienda Hipólito Unanue, tras un proceso de negociación a tres bandas en el que participó el gobierno, la $\mathrm{Mu}-$ nicipalidad y el Tribunal del Consulado, un debate más superficial y formal que real como lo demuestra la falta de garantías fehacientes sobre las que se sustentó la iniciativa y que a la postre fue fundamental para explicar su prematuro fracaso.

El proyecto fiduciario adoptó como referencia teórica el Ensayo Económico sobre el sistema de moneda papel, obra de José Alonso Ortiz publicado en Madrid en 1796. Sin embargo, reveló diferencias fundamentales en aspectos metodológicos con el modelo teóricamente asumido. Los billetes que emitió el Banco Auxiliar nada guardaban en común con los «vales de tesorería» del Ensayo Económico, y numerosas precauciones contempladas en la obra de Alonso Ortiz para el establecimiento del papel moneda, incluyendo la disponibilidad de un fondo de redención y extinción, fueron inobservadas en el proyecto del Protectorado. El objetivo forzado de cubrir mediante papel moneda un déficit monetario anual de cuatro millones y medio de pesos se antojó ilu- 
sorio y temerario. Asimismo, los compromisos con el Banco no fueron satisfechos por el Estado y los particulares, y el complejo sistema de amortizaciones no tardó en manifestar los primeros desajustes serios a partir del segundo plazo de redención cuando fue incapaz de poner en circulación los vales con premio. De forma complementaria, las masivas falsificaciones y la errática actividad de la Casa de la Moneda redujeron aún más los ya de por sí escasos márgenes de maniobra de la nueva entidad.

Antes de la extinción del modelo en el mes de agosto de 1822, el Banco logró poner al servicio del Estado 350.000 pesos con los que sostener la iniciativa militar y aún en 1823 todavía aumentaría sensiblemente esta cantidad. Pero su fracaso, junto a otros factores de carácter político-militar, arrastró al propio Protectorado. San Martín ofreció papel por una plata ausente y logró fondos, a corto plazo, de los que no se disponía para levantar un Estado de nueva base. Pero, desde una perspectiva monetaria, los costes se manifestaron elevados a medio y largo plazo. La falta de confianza que entrañaría para el Perú del siglo XIX la circulación de papel moneda, supondrá un handicap para una economía con graves problemas de crecimiento económico, que no tendrá alternativas al dinero mercancía hasta bien entrado el siglo XX.

\section{FUENTES IMPRESAS Y BIBLIOGRAFÍA}

Bordo, Michel D. y Rosseau, Peter L., «Legal-Political Factors and the Historical Evolution of the Finance-Growth Link», European Review of Economic History, 10/39 (2006): 421-444.

Burzio, Humberto F., La Ceca de Lima, 1565-1824, Madrid, Fábrica Nacional de Moneda y Timbre, 1958.

Bustelo, Francisco y Tortella, Gabriel, «Monetary Inflation in Spain, 1800-1970», Journal European Economic History, 5 (1976): 141-150.

Cameron, Rondo, La banca en las primeras etapas de la industrialización, Madrid, Tecnos, 1974.

Camprubí, Carlos, El Banco de la emancipación, Lima, Villanueva, 1960.

Canga Argüelles, José, Diccionario de Hacienda, Madrid, Imprenta de Marcelino Calero y Portocarrero, 1833.

Cipolla, Carlo M., La odisea de la plata española, Barcelona, Crítica, 1999.

Colección Documental de la Independencia del Perú (CDIP), XIII, 1, Obra de Gobierno y Epistolario de San Martín, Lima, Comisión Nacional del Sesquicentenario de la Independencia del Perú, 1971. 
Colección Documental de la Independencia del Perú (CDIP), XXI, Asuntos Económicos, Informes y Oficios del Tribunal del Consulado, 1, Lima, Comisión Nacional del Sesquicentenario de la Independencia del Perú, 1971.

Contreras, Carlos, El aprendizaje del capitalismo. Estudios de historia económica y social del Perú Republicano, Lima, IEP Ediciones, 2004.

Contreras, Carlos, «Minería y mano de obra en el Perú del siglo XIX», Revista de Historia, 8 (Monterrey, 1989).

Cuenca Esteban, Javier, «Statistics of Spain's Colonial Grade, 1747-1820: New Estimates and Comparisons with Great Britain», Revista de Historia Económica, 26/3 (2008): 323-354.

Chick, Victoria, La macroeconomía según Keynes. Una revisión de la teoría general, Madrid, Alianza Editorial, 1990.

Chust, Manuel (ed.), Las Independencias Iberoamericanas en su laberinto, Valencia, Publicacions de la Universitat de València, 2010.

Dargent, Eduardo, Las Casas de Moneda Españolas en América del Sur, Lima, 2006.

De Haro, Dionisio, La Reforma monetaria del Trienio Constitucional. De la política monetaria ilustrada al reformismo liberal, Madrid, Dykinson, 2006.

Deustua, José, La minería peruana y la iniciación de la República 1820-1840, Lima, Instituto de Estudios Peruanos, 1986.

Domínguez Ortiz, Antonio, Desde Carlos V a la Paz de los Pirineos, 1517-1600, Barcelona, Grijalbo, 1974.

Espina Montero, Álvaro, «Oro, plata y mercurio, los nervios de la monarquía española», Revista de Historia Económica, XIX/3 (2001): 503-538.

Fisher, John R., Commercial Relations betwen Spain and Spanish America in the Era of Free Trade, 1770-1796, Liverpool, Center for Latin American Studies, 1985.

Fisher, John R, Matrícula de los mineros del Perú 1790, Lima, Seminario de Historia Rural Andina UNMSM, 1975.

Flynn, Dennos O., «El desarrollo del primer capitalismo a pesar de los metales preciosos del Nuevo Mundo: una interpretación anti-wallerstein de la España imperial», Revista de Historia Económica, 2 (1984): 29-57.

Fontana, Josep, La crisis del Antiguo Régimen 1808-1833, Barcelona, Crítica, 1992.

Gamio Palacio, Fernando, La Municipalidad de Lima y la emancipación de 1821, Lima, Municipalidad Metropolitana de Lima-Edilibros, 2005 (1. a ed. 1944).

García Camba, Andrés, Memorias para la historia de las armas españolas en el Perú, Madrid, Sociedad Tipográfica de Hortelano y Compañía, 1846, 2 vols.

García-Baquero, Antonio, El comercio colonial en la época del Absolutismo Ilustrado: problemas y debates, Granada, Universidad de Granada, 2003. 
García Martínez, Bernardo, La Casa de Moneda (siglos XVI-XIX), México, Secretaría de Hacienda y Crédito Público, 1970.

Gelman, Jorge, «¿Crisis postcolonial en las economías sudamericanas? Los casos del Río de la Plata y Perú», Enrique Llopis y Carlos Marichal (coords.), Latinoamérica y España 1800-1850. Un crecimiento económico nada excepcional, Madrid, 2009: 25-64.

Hamilton, Earl J., El tesoro Americano y la Revolución de los Precios en España 1501-1650, Crítica, Barcelona, 2000 (1. edición en inglés 1934).

Hausberger, Bernd e Ibarra, Antonio (eds.), Comercio y poder en la América colonial: los consulados de comerciantes, siglos XVII-XIX, Madrid, Celesa, 2003.

Herr, Richard, «El experimento de los vales reales (1780-1808)», Alfonso Otazu (ed.), Dinero y Crédito: (siglos XVI al XIX), Madrid, Moneda y Crédito, 1977.

Irigoin, María Alejandra, "Gresham a caballo: Las raíces monetarias de la fragmentación política de la América española en el siglo XIX», Carlos Contreras, Cristina Mazzeo y Francisco Quiroz (eds.), Guerra, finanzas y regiones en la historia económica del Perú, Lima, Banco Central de Reserva del Perú, 2010: 219-265.

Irigoin, María Alejandra, Finance, Politics and Economics in Buenos Aires, 1820 s1860s: The Political Economy of Currency Stabilitation, Londres, Ph.D. dissertation, London School of Economics, Universidad de Londres, 2000.

Kriedte, Peter, Feudalismo tardío y capital mercantil, Barcelona, Crítica, 1994.

Lazo García, Carlos, Obras escogidas de Carlos Lazo García, Tomo III, La moneda, Lima, Fondo Editorial del Pedagógico San Marcos, 2008.

Levine, Ross, «Finance and growth: theory and evidence», en Ph. Aguion y S.N. Durlauf (eds.), Handbook of Economic Growth, 1A, Amsterdam, Elsevier B.V. (2005): 865-934.

Luqui-Lagleyze, Julio Mario, Por el rey, la fe y la patria: el ejército realista del Perú en la independencia sudamericana, 1818-1825, Madrid, Ministerio de Defensa, Secretaría General Técnica, 2006.

Maldonado, Javier, La formación del capitalismo en el Marco del Jerez, Madrid, Huerga y Fierro, 2000.

Maluquer de Motes, Jordi, «El índice de la producción industrial en Cataluña. Una nueva estimación (1817-1935)», Revista de Historial Industrial, 5 (1994): 45-71.

Marichal, Carlos, La bancarrota del Virreinato. Nueva España y las finanzas del imperio español, 1780-1810, México, Fondo de Cultura Económica, 1999.

Martínez Riaza, Ascensión, La prensa doctrinal en la independencia del Perú: 1811 1824, Madrid, Cultura Hispánica, 1985.

Marx, Karl, Contribución a la crítica de la economía política (2. ${ }^{a}$ edición), Madrid, Lasgon, 1976 [1859]. 
Mazzeo, Cristina, «Los comerciantes, el Consulado y los préstamos al gobierno republicano (Lima-Perú, 1820-1840)», Revista Complutense de Historia de América, 32 (2006): 63-85.

Mitre, Antonio, El monedero de los Andes. Región económica y moneda boliviana en el siglo XIX, México D.F., Instituto Mora, 2004.

Moreyra y Paz Soldán, Manuel, La moneda colonial en el Perú, capítulos de su historia, Lima, Banco Central de la reserva del Perú, 1980.

Morineau, Michel, «Incroyables gazettes et métaux précieux. Le retour des trésors américains d'après les gazettes hollandaises (XVI- XVIII ${ }^{\mathrm{e}}$ siècles)», Cambridge University Press-Maison des Sciences de l'Homme, Cambridge, 1985.

Murray, G., «Guía de los marcos acuñados y ensayadores de la Casa de la Moneda de Madrid (1615-1868)», Numisma, 233 (1993): 295-387.

Paniagua, Valentín, Los orígenes del gobierno representativo en el Perú. Las elecciones (1809-1826), Lima, Pontificia Universidad Católica del Perú, Fondo de Cultura Económica, 2003.

Pascual, Pere, «Moneda e industria. La reforma de 1824 y la acuñación de moneda en Barcelona (1836-1848)», Revista de Historia Industrial, 26 (2004): 57-100.

Pascual, Pere y Sudrià, Carles, «Industrialización, desarrollo financiero y oferta monetaria en Barcelona a mediados del siglo XIX», Investigaciones de Historia Económica, 12 (2008): 45-77.

Peralta, Víctor, «El impacto de las Cortes de Cádiz en el Perú. Un balance historiográfico», Revista de Indias, LXVIII/242, 2008: 67-96.

Prieto Tejeiro, Enrique y De Haro, Dionisio, Ciento cincuenta años de política monetaria en España, Madrid, Dykinson, 2001.

Prieto Tejeiro, Enrique y De Haro, Dionisio, Las reformas monetarias en la primera mitad del siglo XIX. Una aproximación a la historia monetaria de España desde el trienio constitucional hasta la Ley monetaria de 1848, Madrid, Dykinson, 2004.

Prieto Tejeiro, Enrique y De Haro, Dionisio, Historia monetaria de la España contemporánea, Madrid, Delta Ediciones, 2010.

Rosseau, Peter L. y Sylla, Richard, «Financial systems, economic growth and globalization», Michel D. Bordo, Alan M. Taylor y Jeffrey G. Williamson (eds.), Globalization in Historical Perspective, Chicago, University of Chicago Press, 2003: 373-415.

Rosseau, Peter L. y Sylla, Richard, «Financial revolutions and economic growth: Introducing this EEH symposium», Explorations in Economic History, 43 (2006): $1-12$.

Sala i Vila, Núria, Y se armó el tole tole: tributo indígena y movimientos sociales en el Virreinato del Perú, 1784-1814, Ayacucho, Instituto de Estudios Regionales José María Arguedas, 1996. 
Salinas Sánchez, Alejandro, Cuartos y billetes. Crisis monetaria peruana 1821-1879, Lima, Seminario de Historia Rural Andina, UNMSM, 2006.

Sardà Dexeus, Joan, La política monetaria y las fluctuaciones de la economía española en el siglo XIX, Barcelona, Alta Fulla, 1998.

Tedde de Lorca, Pedro, El Banco de San Carlos (1782-1829), Madrid, Alianza Editorial, 1988.

Tedde de Lorca, Pedro, «Oro y plata en España: un ensayo de cuantificación (1770-1850). La economía monetaria española y la independencia de América», E. Llopis y Carlos Marichal (coords.): Latinoamérica y España 1800-1850. Un crecimiento económico nada excepcional. Madrid, 2009: 211-252.

Tepaske, John y Klein, Herbert S., Ingresos y egresos de la Real Hacienda de Nueva España, México, Instituto de Antropología e Historia (Colección Científica, 41), 1986-1988, 2 vols.

Torata, Conde de (Fernando Valdés), «Refutación que hace el mariscal de campo Jerónimo Valdés del manifiesto que el teniente general D. Joaquín de la Pezuela imprimió en 1821 a su regreso del Perú», Documentos para la historia de la guerra separatista del Perú, II, Madrid, Imprenta de la viuda de M. Minuesa de los Ríos, 1895.

Torrente, Mariano, Historia de la revolución hispanoamericana, Madrid, Imprenta de Moreno, 1829-1830, 3 vols.

Vadillo, José Manuel de, Reflexiones sobre la urgencia de remedio a los graves males que hoy se padecen en España por causa de muchas monedas que circulan en ella, Cádiz, Imprenta de Manuel Bosch, 1846.

Vilar, Pierre, «El tiempo del Quijote», Crecimiento y desarrollo. Economía e historia. Reflexiones sobre el caso español, Barcelona, Ariel, 1980.

Vilar, Pierre, «Los primitivos españoles del pensamiento económico: cuantitativismo y bullonismo», Crecimiento y desarrollo. Economía e historia. Reflexiones sobre el caso español, Barcelona, Ariel, 1980a.

Fecha de recepción: 5 de abril de 2011

Fecha de aceptación: 27 de junio de 2011 


\section{The Monetary Policy of San Martin in Peru: paper for absent silver}

The aim of this article is to analyze the monetary initiatives which the government of San Martin was forced to implement in order to resolve its peculiar monetary paradox: machines without silver. The Banco Auxiliar de Papel Moneda played a central role in the new orientation of monetary policy, opening up debates which continued beyond the span of its brief and tortuous existence. Attempts at reform were eventually neutralized and ruined by errors in the initial approach to the problem, an absence of objective conditions and highly questionable management.

KeY WORDS: Monetary history; fiduciary system; precious metals; independence of Peru; minting houses; bank of issue. 